\title{
Effectiveness of Ergonomics Awareness Training Programme in Minimizing The Ergonomic Risk Factors in Dental Surgeons
}

\author{
Abdul Rahim Shaik ${ }^{1, a}$, B.H. SripathiRao ${ }^{2, \text { b }}$, Akhter Husain ${ }^{3, ~ c}$, \\ Juliana LinnetteD'Sa ${ }^{4, d}$ \\ ${ }^{1}$ Associate Professor \& Vice Principal, Yenepoya Physiotherapy College, Yenepoya University, \\ Mangalore, Karnataka, India \\ ${ }^{2}$ Principal / Dean, Yenepoya Dental College, Yenepoya University, Mangalore, Karnataka, India \\ ${ }^{3}$ Professor \& Head, Dept.of Orthodontics, Yenepoya Dental College, Yenepoya University, \\ Mangalore, Karnataka, India
}

${ }^{4}$ Professor, Research in Nursing, Yenepoya Research Center, Yenepoya University, Mangalore, Karnataka, India

ashaikarahim11@gmail.comb drbhsrao@hotmail.comcdrakhter@yahoo.comdsa.julie@gmail.com

Key words: Ergonomics awareness; Ergonomic risk factors; Dental surgeons; Work-related musculoskeletal disorders (WMSDs)

\begin{abstract}
The professional work usually carried out by the dental surgeons results in developing ergonomic risk factors such as forward bends and rotated positions of the body while handling variety of tools. The successful application of ergonomics assures high productivity, avoidance of illnesses and injuries and increased satisfaction among dental surgeons. The study was carried out to find the effectiveness of ergonomics awareness training programme in minimizing the ergonomic risk factors in dental surgeons. For this purpose, one hundred and thirty dental surgeons among post graduate dental students, faculty members and private practitioners from in and around Mangalore city, Southern Karnataka District, India, with more than one year of experience were selected by using non-probability convenience sampling method. A six week of ergonomics awareness training programme for selected dental surgeons was developed and imparted during the training. In order to determine the effectiveness of ergonomics awareness training programme, a pre-tested structured dental work station observation check list was used. The result indicates that, mean post-test scores of manual material handling (0.23), physical energy demands (0.18), instruments (0.00), environment (0.00) and other musculoskeletal demands (1.35) were lower than the mean pre-test scores i.e., 1.98, 1.95, 0.14, 0.01 and 7.53 respectively. Based on the results of the study we conclude that, ergonomics awareness training programme will be effective in minimizing the ergonomic risk factors in dental surgeons.
\end{abstract}

\section{Introduction}

Dental work poses some interesting ergonomic challenges. While performing normal professional work, dental surgeons have to repeatedly change their positions like sitting and standing and at times in one position (static posture) for long periods. With a little attention and creativity, dental surgeons can improve their comfort level on the job.

A poor ergonomically designed workplace may not show immediate ill health effect, because the human body has the capacity for adapting to a poorly designed workplace or structured job. However, the compounding effect of job and workplace deficiencies will surpass the body's coping 
mechanisms causing musculoskeletal discomfort. Good ergonomic design of the workplace is a basic requirement for facilitating the balanced musculoskeletal health that will enable longer, healthier career, increase productivity and minimize Work-related Musculoskeletal Disorders (WMSDs) in dental surgeons[1,2].

Introduction of an effective and result oriented Ergonomics Awareness Training Programme (EATP) shall go a long way in minimizing the ergonomic risk factors by making the dental surgeons aware of healthy working practices along with the use of healthy environment and tools. The objective of the study was to determine the effectiveness of EATP in minimizing the ergonomic risk factors in dental surgeons.

\section{Material and Methods}

The study was conducted in two dental colleges and 20 private dental clinics in and around Mangalore city, Southern Karnataka District, India, using non-probability convenience sampling method. A hundred and thirty dental surgeons among post graduate dental students, faculty members of dental colleges and private practitioners having work experience of more than one year were selected for the study. Dental surgeons who were having moderate to severe pain on the $0-10$ Numeric Pain Rating Scale were included in the study.

In order to find the effectiveness of ergonomics awareness training programme in minimizing the ergonomic risk factors in dental surgeons, a pre-test was administered by using a structured Dental Workstation Observation Check list (DWOC) [3]. Reliability for DWOC was done by using interrater reliability - Pearson's correlation coefficient (r) method and it was found to be 0.673 . The DWOC consisted of manual material handling, physical energy demands, instruments, environment and other musculoskeletal demands.

A six week of EATP for selected working dental surgeons was developed to provide training. It included lecture-discussion session to impart awareness about types of WMSDs, signs and symptoms of WMSDs, contributing or risk factors of WMSDs, ergonomics and physical exercises. In addition to lecture-discussion, demonstration sessions like good postures and positions and chair side directional stretching exercises during mini breaks were arranged with the dental surgeons on one to one basis to make the EATP effective and purposeful. After six weeks of training, each dental surgeon under study was visited during their professional work to find the effectiveness of EATP by using DWOC.

Ethical clearance to conduct the study was obtained from Yenepoya University Ethical Committee. After explaining the purpose of the study, an informed consent was obtained from the participants on voluntary basis. Data were analysed using Statistical Package for Social Sciences (SPSS) version 17.0 software. The analysis was done by using Student's paired t-test and statistical significance was accepted for $\mathrm{p}<0.05$.

\section{Results}

Majority (97.7\%) of mean percentage scores of ergonomic risk factor were found in the area of 'other musculoskeletal demands'. 88.7\% were found in the area of 'manual material handling' and $87.4 \%$ were found in the area of 'physical energy demands'. $3.0 \%$ and $0.7 \%$ of mean percentage scores were found in the area of 'instruments' and 'environment' respectively.

In order to find the mean differences between the pre-test and post-test scores of ergonomic risk factors of dental work station, Student's paired t-test was computed are presented in Table 1 and supplementary data. 
Table 1: Area wise distribution of pre-test and post-test scores of ergonomic risk factors of dental work station $(n=130)$

\begin{tabular}{|c|c|c|c|c|c|c|}
\hline \multirow[t]{3}{*}{ Sl.no } & \multirow[t]{3}{*}{ Ergonomic risk factors } & \multicolumn{3}{|c|}{ Dental workstation } & \multirow{3}{*}{$\begin{array}{c}\mathbf{t} \\
\text { value }\end{array}$} & \multirow{3}{*}{$\begin{array}{c}\mathbf{p} \\
\text { value }\end{array}$} \\
\hline & & Pre-test & Post-test & Difference & & \\
\hline & & Mean \pm SD & Mean \pm SD & Mean \pm SD & & \\
\hline 1. & Manual Material Handling & $1.98 \pm 0.73$ & $0.23 \pm 0.44$ & $1.75 \pm 0.80$ & 24.877 & $<0.001 * *$ \\
\hline 2. & Physical Energy Demands & $1.95 \pm 0.99$ & $0.18 \pm 0.44$ & $1.78 \pm 1.07$ & 18.881 & $<0.001 * *$ \\
\hline 3. & Instruments & $0.14 \pm 0.51$ & $0.00 \pm 0.00$ & $0.14 \pm 0.51$ & 3.098 & $0.002 *$ \\
\hline 4. & Environment & $0.01 \pm 0.09$ & $0.00 \pm 0.00$ & $0.01 \pm 0.09$ & 1.000 & 0.219 \\
\hline 5. & $\begin{array}{l}\text { Other Musculoskeletal } \\
\text { Demands }\end{array}$ & $7.53 \pm 3.37$ & $1.35 \pm 2.14$ & $6.18 \pm 3.74$ & 18.839 & $<0.001 * *$ \\
\hline
\end{tabular}

SD: Standard Deviation $\quad$ t: Student's paired t-test $\quad$ : Probability ${ }^{* * H i g h l y ~ s i g n i f i c a n t ~}{ }^{*}$ Significant

The data in Table 1 show that the mean post-test scores of manual material handling $(0.23)$, physical energy demands (0.18), instruments $(0.00)$, environment $(0.00)$ and other musculoskeletal demands (1.35) were lower than the mean pre-test scores i.e., 1.98, 1.95, 0.14, 0.01 and 7.53 respectively. Mean difference of manual material handling, physical energy demands and other musculoskeletal demands were found to be highly significant $(p<0.001)$ and mean difference of instruments was found to be significant $(\mathrm{p}=0.002)$.

1. It includes any tasks which require a person to lift, lower, pull, hold or carry any object or material.

2. Physical energy demand is the capacity of a physical system to perform work.

3. Instruments are tools used by dental surgeons for the performance of clinical tasks.

4. Refers to the dental workstation which consists of temperature, light, noise, instruments and vibration etc., surrounded by the working environment of dental surgeons.

5. Refers to the physical demands of work activities carried out by dental surgeons which include force, repetition, duration, work postures and local contact stresses.

\section{Discussion}

The design of the working environment of the dental surgeons that has to be adapted both for the patient and for the dental surgeon's requirements can be conceived only after establishing a correct relationship between the dental surgeons and the patients. Most dental surgeonswork with the patient seated in a reclining position and work is usually carried out while seated on a working stool with elevated and unsupported arms, frequently away from the body. In addition the visual adjustments, accuracy and handling of variety of tools during the work result in developing ergonomic risk factors [4]. 
The current study revealed that the ergonomic risk factors in the dental workstation showed that majority $(88.3 \%)$ of the dental surgeons had to 'twist at the waist to handle instruments' followed by 'bending at the waist to handle instruments' (86.3\%). However majority $(72.7 \%)$ of dental surgeons expressed that due to 'high demand in job, they need increased rest in between to avoid excessive fatigue'. $95.7 \%$ of them felt that 'manual jobs require frequent, repetitive motions' followed by 'work postures require frequent bending of the neck' (95.0\%).

Similar observations have been reported from other studies [5,6,7], which indicated that physical load; prolonged abnormal posture and repetition are risk factors which may contribute to WMSDs. Several studies [8, 9, 10] showed that dentistry is physically demanding profession and reported that dental surgeons sit with their heads bent forward in constrained positions for long periods, which coincides with their perception of high physical load at work.

The study revealed that the ergonomic risk factors in the dental work station showed that mean difference of manual material handling, physical energy demands and other musculoskeletal demands were found to be statistically highly significant $(p<0.001)$, whereas mean difference of instruments was found to be statistically significant $(\mathrm{p}=0.002)$.

In most of the studies [11] the dental surgeons are reported to be relatively inactive and a limited number of them use one or other form of physical exercises and ergonomic advices to benefit from the same. Thus there is a scope for further decreasing the prevalence and severity of WMSDs by performing regular specific exercises $[12,13]$. The physiotherapy advice included posturecorrection, ergonomic advice and physical exercises such as stretching exercises, strengthening exercises, aerobic exercises and stress reduction exercises.

An ergonomic systems approach to interventions, focusing on the worker and also on factors within the work organization, appears to be most effective to reduce WMSDs [14]. According to some studies, improvement in the ergonomics of the dental equipment has not served to reduce the incidence of MSDs [15]. The aetiology of musculoskeletal disease is multifactorial, with the involvement of biomechanical, individual and psychosocial factors related to work. Consequently, the preventive strategy must be multifactorial and not only focused on ergonomics. Any useful study on MSDs among dental surgeons should include an analysis of preventive strategies. These strategies in turn should focus on the following areas: ergonomics, breaks at work, general health and physical exercise $[16,17,18]$.

The findings of the study showed that mean post-test scores of working environment with specific reference to dental workstation on five areas of ergonomic risk factors were lower than the mean pre-test scores indicating thereby the effectiveness of the EATP. Further the EATP also helps in minimizing the ergonomic risk factors which are associated with the dental workstation.

The findings of the current study are supported by other studies $[16,17,19]$ which indicate that the ergonomic factors to be taken into account could be summarized as: support of the upper limbs, use of instruments with large handles and working with mechanically adjustable chair having an adjustable backrest. The use of indirect vision and correct patient positioning in the dental chair to avoid awkward or forced neck postures are also important. Proper lighting and the use of systems such as magnifiers and microscopes also help to reduce fatigue and increase productivity.

\section{Conclusion}

We conclude that ergonomic risk factors significantly contribute to WMSDs among dental surgeons. This study also revealed that ergonomics awareness training programme helps in minimizing the ergonomic risk factors in dental surgeons. 


\section{References}

[1] B. Valachi, K. Valachi, Mechanisms leading to musculoskeletal disorders in dentistry, J. Am. Dent. Assoc. 134(2003) 1344-50.

[2] C. Graham, Ergonomics in dentistry, Dent. Today21 (2002) 106-9.

[3] AL Cohen, CC Gjessing, LJ Fine, BP Bernard, JD McGlothlin,Elements of ergonomics programs: A primer based on workplace evaluations of musculoskeletal disorders 1997. Department of Health and Human Services, (National Institute for Occupational Safety and Health) Publication No. 97-117 [cited 2012 22nd August]. Available from: http://www.cdc.gov/niosh/docs/97$117 /$ pdfs/97-117.pdf

[4] F. Goldstep, Dental Ergonomics: Basic Steps to Optimum Health- Academy of Dental Therapeutics and Dentistry, USA, 2004.

[5] C. Nordander, K. Ohlsson, I. Akesson, I. Arvidsson, I. Balogh, G.A. Hansson, et al, Risk of musculoskeletal disorders among females and males in repetitive/constrained work, Ergonomics. 52 (2009) 1226-39.

[6] K. Walker-Bone, C. Cooper, Hard work never hurt anyone: or did it? A review of occupational associations with soft tissue musculoskeletal disorders of the neck and upper limb, Ann. Rheum. Dis. 64 (2005) 1391-6.

[7] N. Yamalik, Musculoskeletal disorders (MSDs) and dental practice part 2. Risk factors for dentistry, magnitude of the problem, prevention, and dental ergonomics, Int. Dent. J. 57 (2007) 4554.

[8] D. Jonker, B. Rolander, I. Balogh, Relation between perceived and measured workload obtained by long-term inclinometry among dentists, Appl. Ergon. 40 (2009) 309-15.

[9] L. Finsen, H. Christensen, M. Bakke, Musculoskeletal disorders among dentists and variation in dental work, Appl. Ergon.29 (1998) 119-25.

[10] I. Akesson, G.A. Hansson, I. Balogh, U, Moritz, S. Skerfving, Quantifying work load in neck, shoulders and wrists in female dentists, Int. Arch. Occup .Environ. Health.69 (1997) 461-74.

[11] EJ Kay, JC Lowe, A survey of stress levels, self-perceived health and health-related behaviours of UK dental practitioners in 2005, Br Dent J. 204(11):E19 (2008) 622-3.

[12] BP Shrestha, GK Singh, SR Niraula, Work related complaints among dentists, J Nepal Med Assoc. 47(170) (2008) 77-81.

[13] P Lindfors, U Von Thiele, U Lundberg, Work characteristics and upper extremity disorders in female dental health workers, J Occup Health. 48(3) (2006) 192-7.

[14] P Buckle, Adapting work to people: New approaches to preventing musculoskeletal disorders, Health and Safety Congress, 2002.

[15] LM Rucker, S Sunell, Ergonomic risk factors associated with clinical dentistry, J Calif Dent Assoc. 30(2) (2002) 139-48.

[16] B Valachi, K Valachi, Preventing musculoskeletal disorders in clinical dentistry: strategies to address the mechanisms leading to musculoskeletal disorders, J Am Dent Assoc. 134(12) (2003) 1604-12. 
[17] B Valachi, K Valachi, Mechanisms leading to musculoskeletal disorders in dentistry,J Am Dent Assoc. 134(10) (2003) 1344-50.

[18] N Andrews, G Vigoren, Ergonomics: muscle fatigue, posture, magnification, and illumination, CompendContinEduc Dent. 23(3) (2002) 261-6, 268,270,274.

[19] AP Verhagen, SM Bierma-Zeinstra, A Feleus, C Karels, S Dahaghin, L Burdorf, et al, Ergonomic and physiotherapeutic interventions for treating upper extremity work related disorders in adults, Cochrane Database Syst Rev. (1) (2004) Cochrane AN: CD003471. 